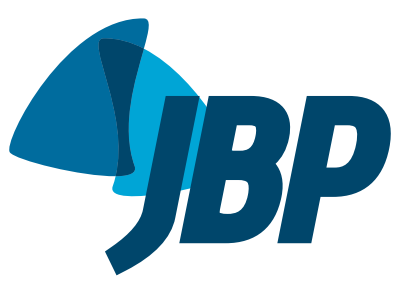

1. Divisão de Pneumologia, Instituto do Coração - InCor - Hospital das Clínicas, Faculdade de Medicina, Universidade de São Paulo, São Paulo (SP) Brasil.

2. Serviço de Radiologia Intervencionista, Instituto do Coração - InCor - Hospita das Clínicas, Faculdade de Medicina, Universidade de São Paulo, São Paulo (SP) Brasil.

a. iD http://orcid.org/0000-0002-2199-9525

b. (iD) http://orcid.org/0000-0002-8756-0400

c. (iD) http://orcid.org/0000-0001-8642-4725

d. (iD) http://orcid.org/0000-0002-9373-3937

e. (iD) http://orcid.org/0000-0002-2940-9016

f. (iD http://orcid.org/0000-0001-9844-6833

g. (iD) http://orcid.org/0000-0002-7702-6810

h. (iD) http://orcid.org/0000-0002-8642-5354

Submitted: 28 May 2018

Accepted: 29 October 2018.

Study carried out at the Instituto do

Coração - InCor - Hospital das Clínicas,

Faculdade de Medicina, Universidade de

São Paulo, São Paulo (SP) Brasil.

\section{Pulmonary arteriovenous malformations: diagnostic and treatment characteristics}

\author{
William Salibe-Filho, ${ }^{1, a}$, Bruna Mamprim Piloto, ${ }^{1, b}$, Ellen Pierre de Oliveira, ${ }^{1, c}$, \\ Marcela Araújo Castro ${ }^{1, \mathrm{~d}}$, Breno Boueri Affonso ${ }^{2, e}$, \\ Joaquim Maurício da Motta-Leal-Filho ${ }^{2, \mathrm{f}}$, Edgar Bortolini²,s, Mário Terra-Filho ${ }^{1, \mathrm{~h}}$
}

\begin{abstract}
Objective: To present a case series of pulmonary arteriovenous malformations (PAVMs), describing the main clinical findings, the number/location of pulmonary vascular abnormalities, the clinical complications, and the treatment administered. Methods: This was a retrospective observational study evaluating patients with PAVM divided into two groups: hereditary hemorrhagic telangiectasia (HHT); and idiopathic PAVM (iPAVM). Results: A total of 41 patients were selected for inclusion, but only 33 had PAVMs. After clinical evaluation, 27 and 6 were diagnosed with HHT and iPAVM, respectively. In the $\mathrm{HHT}$ group, the mean age was 49.6 years and $88.9 \%$ were female. In that group, 4 patients had an $\mathrm{SpO}_{2}$ of $<90 \%$ and the most common clinical finding was epistaxis. In the iPAVM group, the mean age was 48.1 years and $83.3 \%$ were female. In that group, 3 patients had an $\mathrm{SpO}_{2}$ of $<90 \%$. Computed tomographic pulmonary angiography showed that most of the PAVMs were in the lower lobes: $56.4 \%$ in the HHT group and $85.7 \%$ in the iPAVM group. Embolization was performed in 23 patients (in both groups). At this writing, 10 patients are scheduled to undergo the procedure. One of the patients who underwent embolization was subsequently referred for pulmonary resection. Conclusions: In both of the PAVM groups, there was a predominance of women and of fistulas located in the lower lobes. Few of the patients had respiratory symptoms, and most had an $\mathrm{SpO}_{2}>90 \%$. The treatment chosen for all patients was percutaneous transcatheter embolization.
\end{abstract}

Keywords: Telangiectasia, hereditary hemorrhagic; Arteriovenous malformations/ diagnosis; Arteriovenous malformations/therapy.

\section{INTRODUCTION}

Pulmonary arteriovenous malformations (PAVMs) are abnormal direct connections between a pulmonary artery and a pulmonary vein, ${ }^{(1)}$ presenting with a variety of clinical manifestations. A right-to-left shunt, bypassing the capillary bed, compromises oxygenation and can lead to hypoxemia.(2) Patients with PAVMs are prone to infections (including cerebral, hepatic, and splenic abscesses), as well as ischemic stroke, which are due to abnormal vascular communications bypassing the filtering capacity of the capillary bed and allowing bacteria and thrombi to pass directly from the venous to the arterial blood.

One of the most common causes of PAVM is hereditary hemorrhagic telangiectasia $(\mathrm{HHT}),^{(3,4)}$ which is also known as Osler-Weber-Rendu syndrome. An autosomal dominant disorder that is globally distributed, $\mathrm{HHT}$ has an estimated prevalence of $1: 5,000$ and is characterized by epistaxis and telangiectasia of different parts of the body, sometimes being accompanied by cerebral arteriovenous malformations (AVMs), PAVMs, gastrointestinal AVMs, or hepatic AVMs. (3) Because HHT is underdiagnosed, the etiology of bleeding often remains unknown, nasal and gastrointestinal bleeding predominating. Many patients develop anemia and receive blood transfusions but are unaware that they have AVMs that can be treated.

The diagnosis of HHT is primarily based on the International Clinical Diagnostic (Curaçao) Criteria, ${ }^{(1)}$ which are clinical and radiological criteria for the diagnosis of HHT. HHT accounts for $80-95 \%$ of all PAVMs. ${ }^{(1,5)}$ When a diagnosis of HHT cannot be established, PAVMs are classified as idiopathic (iPAVMs). Pulmonary hypertension $(\mathrm{PH})$ is rarely present and can be due to increased pulmonary vascular flow, hepatic AVMs, or anemia. ${ }^{(6)}$ A small proportion of cases are associated with genetic abnormalities. (7,8) $^{2}$

In the past, PAVMs were treated surgically, the rate of complications being high. ${ }^{(9,10)}$ In 1977, Porstmann ${ }^{(11)}$ performed the first catheter embolization using coils, introducing the possibility of percutaneous transcatheter embolization for the treatment of PAVMs. Because percutaneous transcatheter embolization is much less invasive than surgery, it reduces the length of hospital stay and the number of complications. Even in asymptomatic patients, PAVMs should be treated with embolization if they have a feeding artery diameter $>3 \mathrm{~mm}$, in order to prevent infectious complications and strokes. ${ }^{(3,12)}$ Surgery is currently reserved for cases in which percutaneous

Correspondence

to: William Salibe Filho. Departamento de Pneumologia, Instituto do Coração, Hospital das Clínicas, Universidade de São Paulo, Avenida Dr. Enéas de Carvalho Aguiar, 44, CEP 05403-000, São Paulo, SP, Brasil

Tel.: 55112661 5695. E-mail: wsalibe@usp.br

Financial support: None. 
transcatheter embolization fails, feeding artery diameter is too large, or vascular anatomy precludes treatment with embolization. ${ }^{(13)}$ Lung transplantation should be reserved for exceptional cases. ${ }^{(4)}$

In the present study, we sought to present a case series of PAVM patients followed at a pulmonology outpatient clinic in the city of São Paulo, Brazil, describing the main clinical findings, the number/ location of PAVMs, the clinical complications, and the treatment administered.

\section{METHODS}

\section{Study population}

This was a retrospective observational study, in which electronic medical records were reviewed for all patients referred to the Pulmonary Circulation Outpatient Clinic of the University of São Paulo Hospital das Clínicas Instituto do Coração (InCor, Heart Institute) between 2010 and 2017 for AVM evaluation. After clinical evaluation, the Curaçao Criteria(1) were used in order to confirm the diagnosis of HHT: 1) presence of epistaxis; 2) presence of telangiectasias, particularly on the lips, tongue, and fingers; 3) presence of cerebral AVMs, PAVMs, or gastrointestinal AVMs; and 4) a family history of HHT. Patients meeting at least three of the aforementioned criteria were diagnosed with definite $\mathrm{HHT}$. $^{(1,14)}$ The remaining patients were diagnosed with iPAVM. After clinical examination, all patients underwent chest $\mathrm{x}$-ray, chest CT angiography, cranial CT angiography, transthoracic echocardiography, and $\mathrm{SpO}_{2}$ measurement.

Percutaneous transcatheter embolization was performed with an Amplatzer ${ }^{\circledR}$ device (AGA Medical Corporation, Golden Valley, MN, USA) or coils, depending on their availability. The InCor protoco for percutaneous transcatheter embolization includes the following: local anesthesia; cardiopulmonary monitoring; and systemic unfractionated heparin administered as a bolus of 2,500 IU per hour, approximately. The procedure is performed without antibiotic prophylaxis.

\section{RESULTS}

\section{Clinical and demographic data}

A total of 41 patients were selected for inclusion in the present study. Of those, 8 were excluded: 7 met three of the Curaçao Criteria for HHT but had no PAVMs, and 1 met only one of the Curaçao Criteria (i.e., a family history of $\mathrm{HHT}$ ). Of the remaining 33 patients, 27 met the diagnostic criteria for HHT and 6 were classified as having iPAVM. Therefore, two groups were formed: the HHT group, comprising 27 patients, and the iPAVM group, comprising 6 patients (Figure 1).

Demographic data had been collected at the first outpatient visit. In the HHT group, the mean age was $49.6 \pm 16.9$ years and females predominated ( $n=24)$. Of the 27 patients in the HHT group, 24 $(89.0 \%)$ had telangiectasias, predominantly on the lips and tongue (Figure 2). None of the patients had digital clubbing. In the initial evaluation, 5 patients $(18.5 \%)$ had dyspnea. Of those, 4 were functional class II and 1 was functional class III. Of the $5 \mathrm{HHT}$ patients who presented with dyspnea, 4 had an $\mathrm{SpO}_{2}$ of < $90 \%$ (mean, $84.5 \%$; range, $78.0-89.0 \%$ ) and 1 had an $\mathrm{SpO}_{2}>90 \%$. Another 2 patients had an $\mathrm{SpO}_{2}$ of $<90 \%$ but no respiratory symptoms. The most common clinical finding in the HHT group was epistaxis (in $100 \%$ ). None of the patients in the group reported hemoptysis. Cranial CT angiography revealed cerebral AVMs in only 2 (7\%) of the patients in the HHT group. None of the patients had a history of gastrointestinal bleeding.

In the iPAVM group, the mean age was $48.1 \pm 17.3$ years and females predominated $(n=5)$. Of the 6 patients in the group, 4 had dyspnea. Of those, 2 were functional class II, 1 was functional class III, and 1 was functional class IV. Of the 4 iPAVM patients who presented with dyspnea, 3 had an $\mathrm{SpO}_{2}$ of $<90 \%$ (mean, 83.0\%; range, 77.0-89.0\%). One patient had an $\mathrm{SpO}_{2}$ of $<90 \%$ but reported no dyspnea, and 2 had an $\mathrm{SpO}_{2}>90 \%$ and no respiratory symptoms (Table 1). None of the patients in the group had recurrent epistaxis.

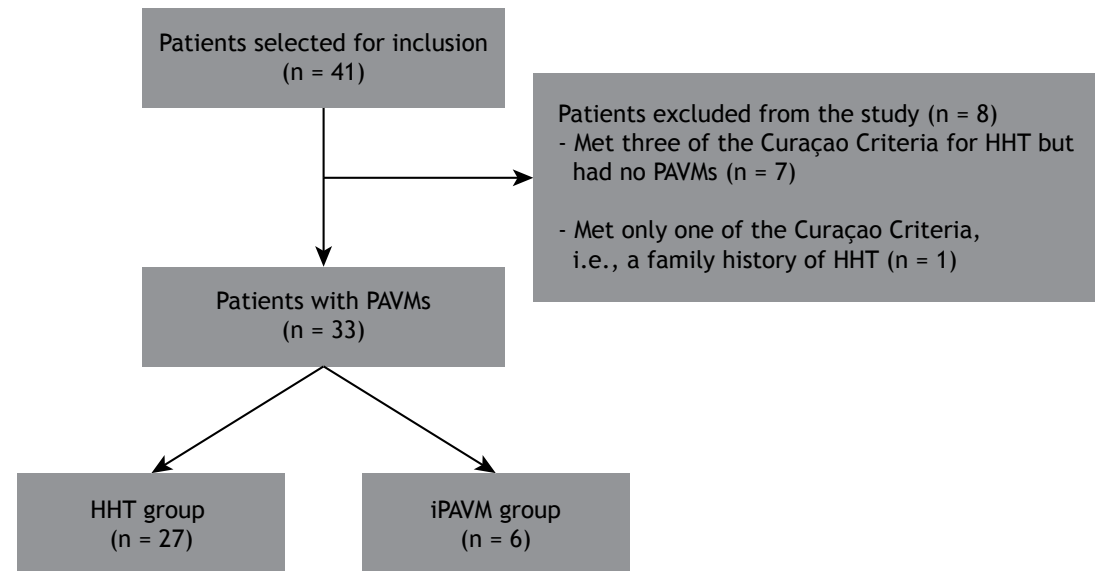

Figure 1. Patients with pulmonary arteriovenous malformations (PAVMs) divided into two groups. HHT: hereditary hemorrhagic telangiectasia; and iPAVM: idiopathic pulmonary arteriovenous malformation. 


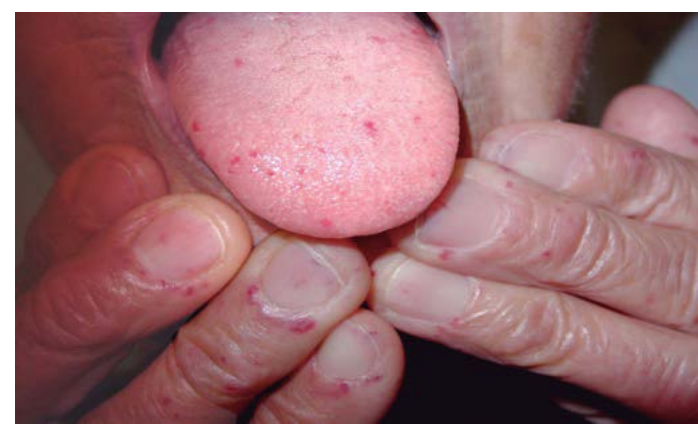

Figure 2. Photograph showing telangiectasias on the lips and fingers of a patient with hereditary hemorrhagic telangiectasia.

\section{Echocardiography, chest CT angiography,} and cranial CT angiography

A total of 25 patients $(83.3 \%)$ underwent echocardiography. One patient (in the HHT group) was suspected of having $\mathrm{PH}$. The patient in question underwent echocardiography twice, pulmonary artery systolic pressure being above the reference value on both examinations $(48 \mathrm{mmHg}$ and $53 \mathrm{mmHg}$ ). A total of 7 patients underwent microbubble contrast-enhanced echocardiography. In all 7, the microbubble contrast agent passed from the right to the left side of the heart after the third cycle, the presence of intrapulmonary shunt therefore being confirmed. Shortly after being examined, 1 patient experienced visual disturbance and headache lasting approximately $1 \mathrm{~h}$, with good clinical progression. Two patients had cerebral AVMs.

Chest CT angiography showed 101 PAVMs in the HHT group and 7 in the IPAVM group. Of the 101 PAVMs observed in the HHT group, 14 (13.8\%) were located in the right upper lobe, $15(14.8 \%)$ were located in the middle lobe, $35(34.6 \%)$ were located in the right lower lobe, $5(4.9 \%)$ were located in the left upper lobe, $11(10.8 \%)$ were located in the lingula, and 22 $(21.7 \%)$ were located in the left lower lobe (Figure $3 \mathrm{~A})$. Of the 7 PAVMs observed in the PAVM group, $1(14.2 \%)$ was located in the right upper lobe, 3 $(42.9 \%)$ were located in the right lower lobe, and 3 $(42.9 \%)$ were located in the left lower lobe. Of the 6 patients in the IPAVM group, 5 had 1 PAVM and 1 had two (Table 1). As can be seen in Figure 3B, the lower lobes were more commonly affected than the upper lobes in the HHT group ( $56.4 \%$ vs. $43.6 \%$ ) and in the iPAVM group ( $85.7 \%$ vs. $14.2 \%)$.

\section{Complications}

All patients were evaluated for complications of PAVMs. One patient had cerebral, subphrenic, and psoas abscesses. Hemothorax and pleural empyema were found in 2 patients from the same family, and bacterial endocarditis was found in 1 patient.

\section{Treatment}

\section{Embolization}

All patients who underwent embolization had PAVMs with a feeding artery diameter of $\leq 20 \mathrm{~mm}$ (Figures
4 and 5), Amplatzer ${ }^{\circledR}$ devices and coils being used depending on their availability. Of the 27 patients in the HHT group, $8(30.7 \%)$ required two or more embolization procedures for the treatment of PAVMs, 10 underwent one procedure, and 9 were scheduled to undergo treatment at this writing ( 1 having undergone one procedure in another country). In the IPAVM group, embolization was successful in 4 patients, their $\mathrm{SpO}_{2}$ having improved. One patient had a complex PAVM and underwent three embolization procedures. All three were unsuccessful, the patient therefore being referred for pulmonary lobectomy. At this writing, 1 patient was scheduled to undergo treatment. No serious complications occurred during the procedures, and only 2 patients experienced pleuritic chest pain $48 \mathrm{~h}$ after the procedure, improving with the use of analgesics.

\section{Post-treatment follow-up}

All patients were followed at the Pulmonary Circulation Outpatient Clinic of the InCor and evaluated three months after the procedure, at which time the need for another embolization procedure was assessed. After completing the treatment, patients underwent annual clinical evaluations. At this writing, there were no deaths among the study population.

\section{DISCUSSION}

It is known that PAVMs can cause serious complications, such as stroke and brain abscess, as well as massive hemorrhage. To our knowledge, ours is the first study in Latin America to report a large number of PAVM cases of varying etiologies. ${ }^{(15,16)}$ Females predominated in the two study groups. Patients with HHT were more symptomatic than those with iPAVM, as well as having more PAVMs. For all patients, the initial treatment was percutaneous transcatheter embolization with coils or Amplatzer ${ }^{\circledR}$ devices.

Of the 41 patients selected for inclusion, 33 had PAVMs. Of those, $27(87 \%)$ and $6(13 \%)$ were diagnosed with HHT and iPAVM, respectively. This constitutes evidence that HHT is the primary cause of PAVMs, as reported elsewhere. ${ }^{(1,4)} \mathrm{HHT}$ is a hereditary vascular disorder whose primary symptom is epistaxis, seen in more than $90 \%$ of patients. ${ }^{(13)}$ The fact that $100 \%$ of the HHT patients in the present study reported epistaxis is evidence that recurrent epistaxis is an important feature of HHT. In contrast, none of the iPAVM patients in the present study reported epistaxis. Therefore, findings of PAVM and recurrent epistaxis should raise the suspicion of HHT.

With regard to hypoxemia, an $\mathrm{SpO}_{2}$ of $<90 \%$ was found in $15 \%$ of the HHT patients and in $66 \%$ of the iPAVM patients in the present study. This finding is important when PAVM cases of varying etiologies are compared, because the number of PAVMs at diagnosis and treatment initiation is highest in patients with $\mathrm{HHT}$. ${ }^{(1)}$ One possible explanation for our finding of a much lower proportion of patients with an $\mathrm{SpO}_{2}$ of $<$ 


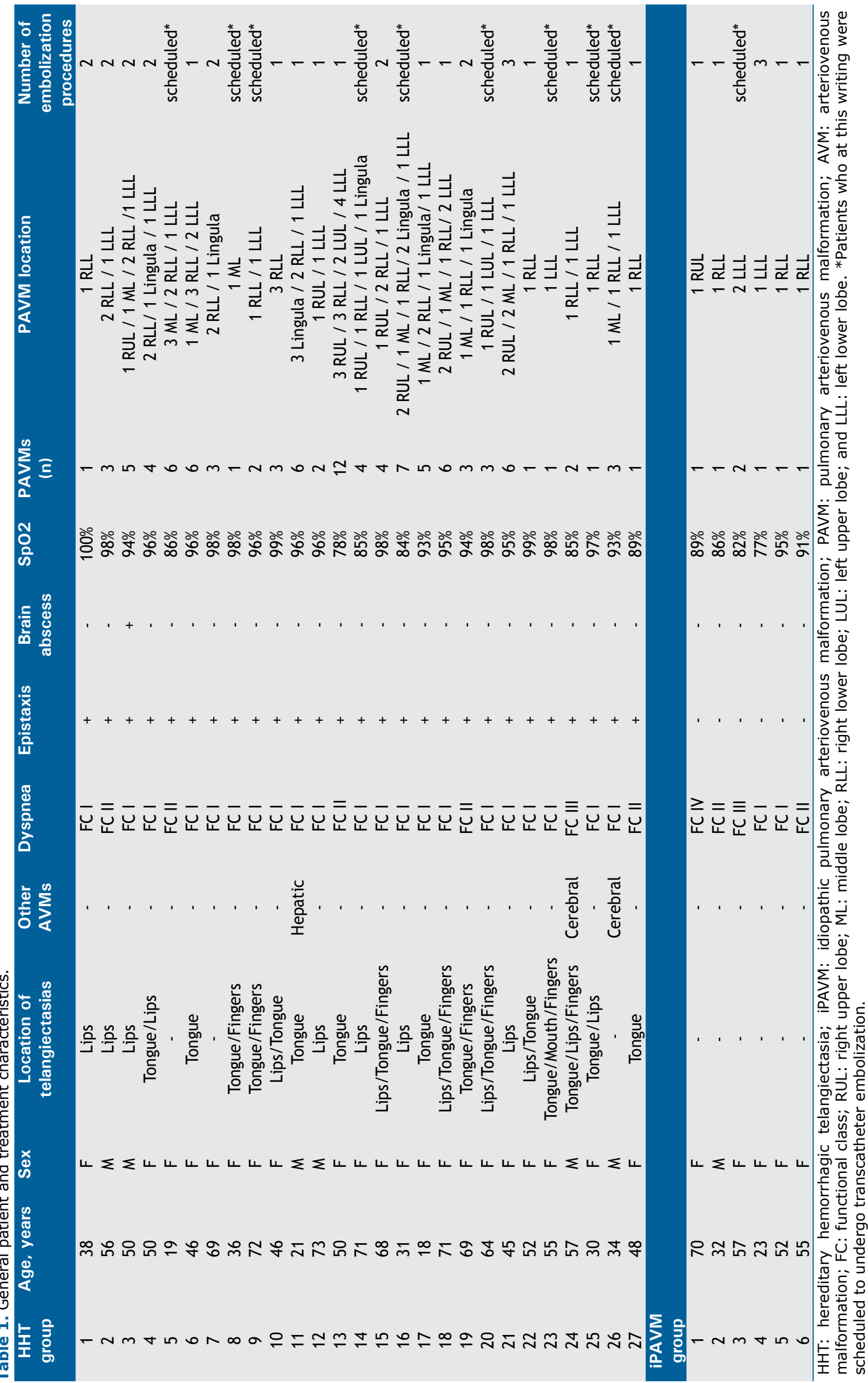


$90 \%$ in the HHT group is that, although patients with $\mathrm{HHT}$ present with more PAVMs than do those with iPAVM, pulmonary shunt is more severe in the latter.

In the present study, PAVMs were predominantly located in the lower lobes, a finding that is consistent with those of another study. ${ }^{(1)}$ This finding suggests that there was no significant relationship between PAVM location and the fact that the proportion of patients with hypoxemia was higher in the iPAVM group than in the HHT group. It is of note that the patients who had reduced $\mathrm{SpO}_{2}$ levels were mildly

(A)

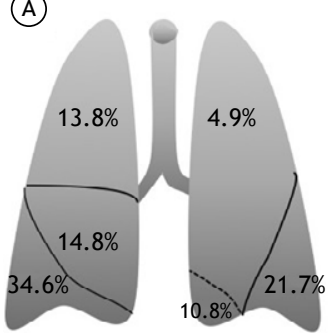

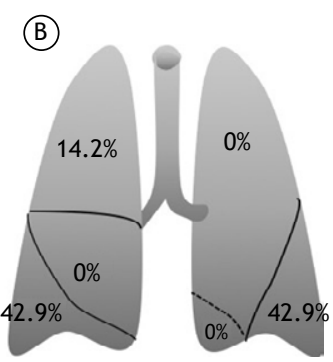

Figure 3. In A, location of pulmonary arteriovenous malformations in the group of patients with hereditary hemorrhagic telangiectasia $(n=101)$. In $B$, location of pulmonary arteriovenous malformations in the group of patients with idiopathic pulmonary arteriovenous malformations $(n=7)$. symptomatic and had dyspnea on exertion only; this might be due to an adaptive response to hypoxemia (i.e., acclimatization). ${ }^{(17,18)}$

It has been reported that $10-20 \%$ of patients with HHT have cerebral AVMs. ${ }^{(13)}$ Patients with HHT should be screened for cerebral AVMs because of the risk of serious complications such as bleeding, with an estimated risk of $0.5 \%$ per year. ${ }^{(3)}$ In the present study, cerebral AVMs were found in 2 patients (7\%). This is probably due to the fact that magnetic resonance imaging of the brain and cerebral arteriography were not performed, cranial CT angiography being the only examination performed.

Of the 27 patients with HHT in the present study, 2 (7.4\%) had infectious complications: brain abscess, in 1 , and bacterial endocarditis (occurring within 1 year after percutaneous transcatheter embolization), in 1 . The aforementioned patient and another from the same family had pleural empyema. In order to prevent infections, patients with PAVMs should receive antibiotic prophylaxis for dental procedures. ${ }^{(13)}$ It is extremely important to screen HHT patients for infectious complications, which in some cases are the first manifestations of $\mathrm{HHT}$, appearing before the diagnosis of PAVM is made. ${ }^{(6)}$

Another finding in patients with $\mathrm{HHT}$ is $\mathrm{PH}$, which can be due to hepatic AVMs, ${ }^{(19)}$ anemia, increased
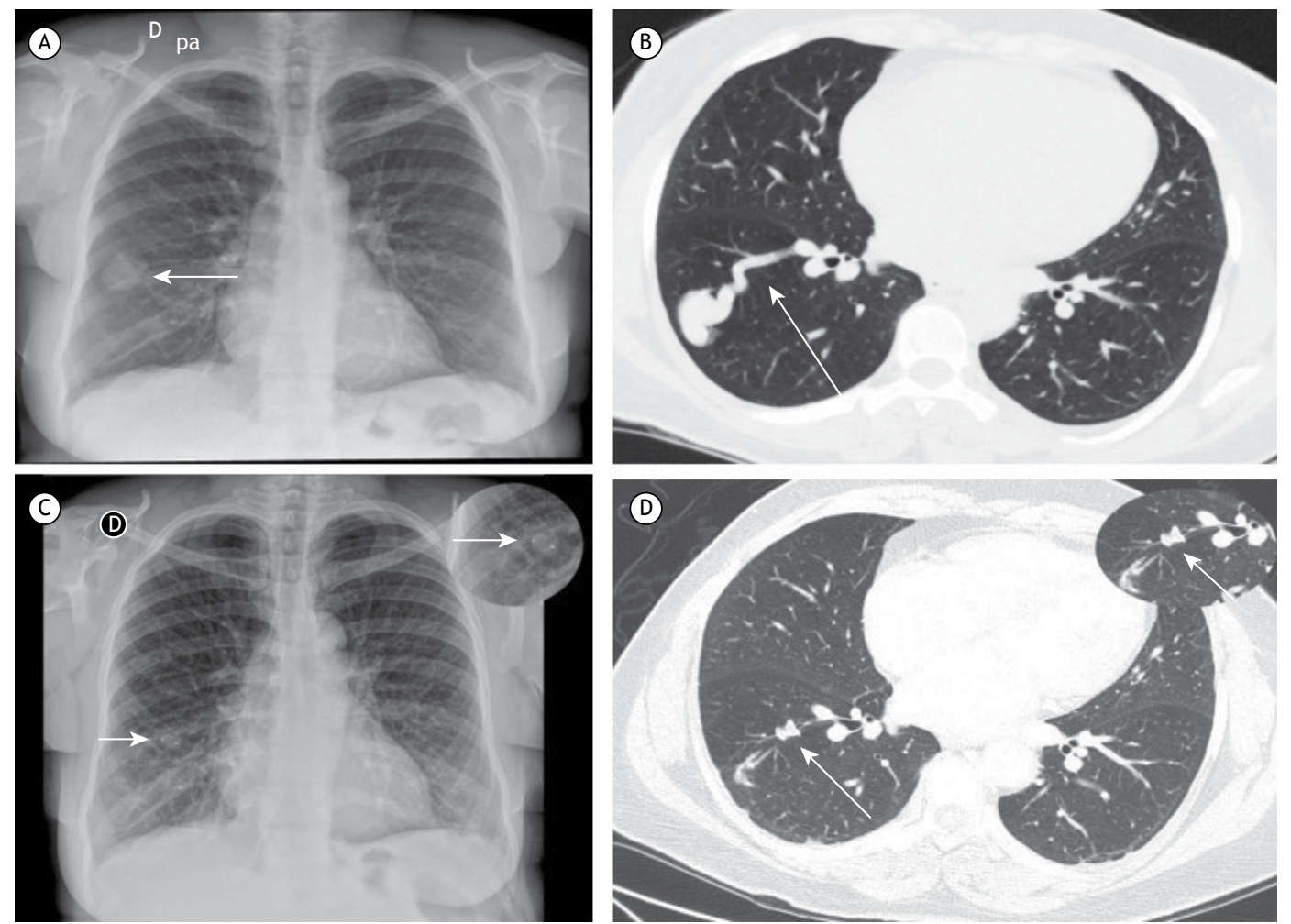

Figure 4. In $A$, chest $X$-ray taken before embolization and showing a nodule in the lower third of the right hemithorax (arrow). In B, chest CT angiography performed before embolization and showing an arteriovenous malformation in the right lower lobe (arrow). In C, chest X-ray taken after embolization and showing an Amplatzer ${ }^{\circledR}$ device in the lower third of the right hemithorax (arrow; see also the enlarged inset). In D, chest CT angiography performed after embolization and showing a reduction in pulmonary arteriovenous malformation sac size, as well as the Amplatzer ${ }^{\circledR}$ device in the right lower lobe (arrow; see also the enlarged inset). 

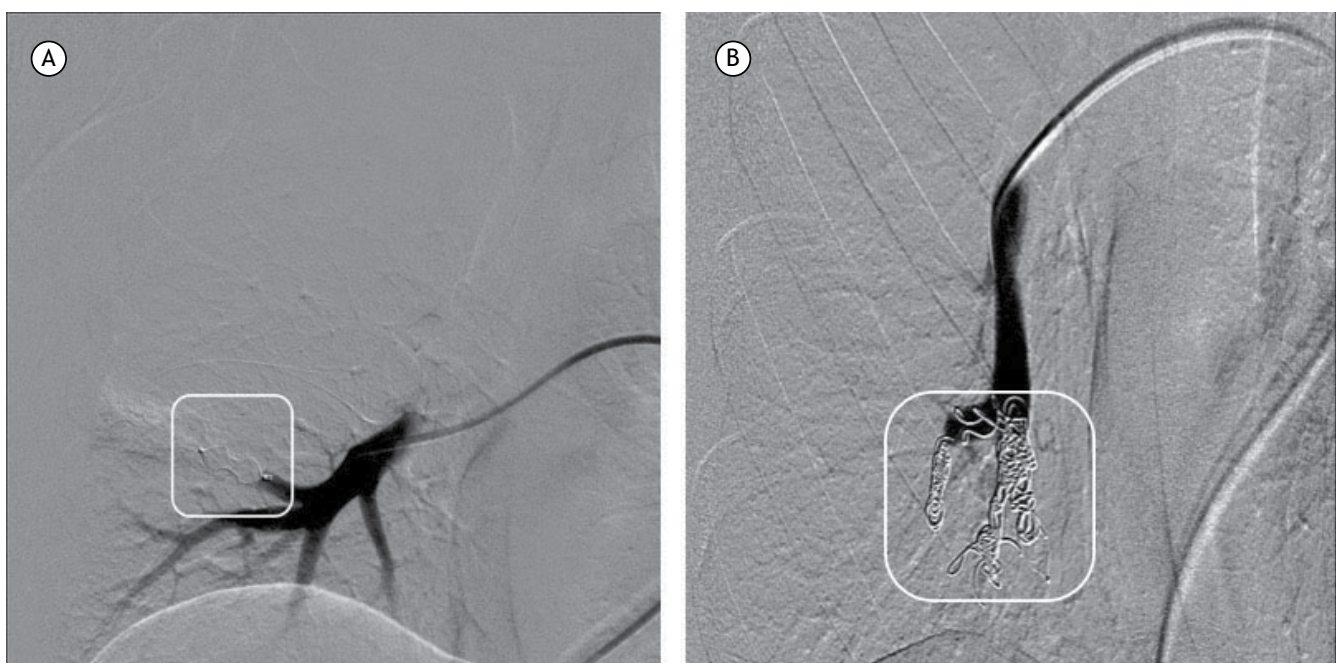

Figure 5. Arteriography performed after embolization. In A, Amplatzer ${ }^{\circledR}$ device; in B, coils.

pulmonary vascular flow, or genetic abnormalities, the last of the four affecting the ENG gene on chromosome 9 or the ACVRL1 gene on chromosome $12 .{ }^{(20)}$ In the present study, $\mathrm{PH}$ was suspected in 1 patient $(3.7 \%)$, who underwent echocardiography twice and had no anemia. No right heart catheterization was performed to confirm the diagnosis of $\mathrm{PH}$.

Transcatheter embolization is the best treatment option for patients with PAVMs, including asymptomatic patients. ${ }^{(21)}$ It is an important treatment option because it improves hypoxemia and prevents ischemic stroke and infectious complications caused by right-to-left shunt. (22-24) Percutaneous transcatheter embolization is currently the most widely used treatment for AVMs in patients with $\mathrm{HHT}$ and in those with iPAVMs. ${ }^{(1)}$ Multiple PAVMs can be treated during a single procedure; however, in patients with many PAVMs and in those with several complex PAVMs, it is best to perform several embolization procedures on different days. ${ }^{(13)}$ In the present study, $30.7 \%$ of the patients underwent two or more embolization procedures on separate occasions, at least three weeks apart. Complications included pleuritic chest pain $48 \mathrm{~h}$ after the procedure in 2 patients $(6.25 \%)$, who improved with pharmacological treatment. Pleuritic chest pain is considered a benign complication, occurring in $10 \%$ of cases; it is a transient complication, being associated with diffuse or peripheral PAVMs. ${ }^{(25)}$ Major complications include pulmonary infarction, device migration, gas embolism, transient angina, cardiac arrhythmia, and pneumothorax, which have been reported to occur in approximately $1 \%$ of cases when treatment is performed at experienced centers. ${ }^{(13)}$ Contraindications to percutaneous embolization include pregnancy, $\mathrm{PH}$, and kidney failure. ${ }^{(26)}$ However, in some cases, the benefits outweigh the risks, and the decision to perform the procedure should be made on a case-by-case basis. ${ }^{(27)}$ At this writing, 1 patient with $\mathrm{PH}$ was under evaluation for possible embolization, an interventional radiology team being involved in the decision-making process.

A follow-up evaluation should be carried out 3-6 months after the embolization procedure, consisting of clinical examination and imaging (e.g., a chest X-ray). ${ }^{(6)}$ Although $\mathrm{SpO}_{2}$ increases shortly after the procedure, a reduction in PAVM sac size and complete resolution of the PAVM occur within 6 months. $(23,28,29)$ There is no consensus regarding when CT angiography should be performed again. ${ }^{(6)}$

Surgical resection is reserved for complex cases ${ }^{(13)}$ or cases in which embolization is unsuccessful. Of the 33 PAVM patients in the present study, only 1 was referred for surgical resection (after three failed embolization procedures).

The limitations of the present study include its retrospective design at a single institution (a pulmonary circulation outpatient clinic) and the fact that the number of patients in each group was markedly different, precluding a straightforward between-group comparison. Despite variations in the diagnosis, treatment, and follow-up of PAVMs, the best option for patients with PAVMs is to be followed by a multidisciplinary team at a specialized center. ${ }^{(17,27,30,31)}$

In summary, females predominated in our study, as did PAVMs located in the lower lobes. Few clinical complications were encountered. The majority of patients with HHT had multiple PAVMs and epistaxis, as well as having no respiratory symptoms or hypoxemia. The majority of patients with iPAVMs had only one PAVM, as well as having dyspnea and hypoxemia. In all cases, the initial treatment was percutaneous transcatheter embolization.

\section{REFERENCES}

1. Wong $H H$, Chan RP, Klatt $R$, Faughnan ME. Idiopathic pulmonary arteriovenous malformations: clinical and imaging 
2. Shovlin CL. Hereditary haemorrhagic telangiectasia: pathophysiology, diagnosis and treatment. Blood Rev. 2010;24(6):203-19. https://doi. org/10.1016/j.blre.2010.07.001

3. Faughnan ME, Palda VA, Garcia-Tsao G, Geisthoff UW, McDonald J, Proctor DD, et al. International guidelines for the diagnosis and management of hereditary haemorrhagic telangiectasia. J Med Genet. 2011;48(2):73-87. https://doi.org/10.1136/jmg.2009.069013

4. Shovlin CL. Pulmonary arteriovenous malformations. Am J Respir Crit Care Med. 2014;190(11):1217-28. https://doi.org/10.1164/ rccm.201407-1254Cl

5. Gupta P, Mordin C, Curtis J, Hughes JM, Shovlin CL, Jackson JE. Pulmonary arteriovenous malformations: effect of embolization on right-to-left shunt, hypoxemia, and exercise tolerance in 66 patients. AJR Am J Roentgenol. 2002;179(2):347-55. https://doi.org/10.2214/ ajr.179.2.1790347

6. Shovlin CL, Condliffe R, Donaldson JW, Kiely DG, Wort SJ; British Thoracic Society. British Thoracic Society Clinical Statement on Pulmonary Arteriovenous Malformations. Thorax. 2017;72(12):11541163. https://doi.org/10.1136/thoraxjnl-2017-210764

7. Vorselaars VM, Velthuis S, Snijder RJ, Vos JA, Mager JJ, Post MC Pulmonary hypertension in hereditary haemorrhagic telangiectasia. World J Cardiol. 2015;7(5):230-7. https://doi.org/10.4330/wjc. v7.i5.230

8. Chadha D, Handa A, Kumar A. Pulmonary hypertension in a patient with hereditary haemorrhagic telangiectasia. BMJ Case Rep. 2013;2013. pii: bcr2012008352.

9. Pollak JS, Saluja S, Thabet A, Henderson KJ, Denbow N, White RI Jr. Clinical and anatomic outcomes after embolotherapy of pulmonary arteriovenous malformations. J Vasc Interv Radiol. 2006;17(1):35-44; quiz 45. https://doi.org/10.1097/01.RVI.0000191410.13974.B6

10. Faughnan ME, Lui YW, Wirth JA, Pugash RA, Redelmeier DA, Hyland $\mathrm{RH}$, et al. Diffuse pulmonary arteriovenous malformations: characteristics and prognosis. Chest. 2000;117(1):31-8. https://doi. org/10.1378/chest.117.1.31

11. Porstmann W. Therapeutic embolization of arteriovenous pulmonary fistula by catheter technique. In: Kelop O, editor. Current Concepts in Pediatric Radiology. Berlin: Springer-Verlag; 1977. https://doi. org/10.1007/978-1-4471-1288-4_3

12. White RI Jr, Lynch-Nyhan A, Terry P, Buescher PC, Farmlett EJ, Charnas $L$, et al. Pulmonary arteriovenous malformations: techniques and long-term outcome of embolotherapy. Radiology. 1988;169(3):663-9. https://doi.org/10.1148/radiology.169.3.3186989

13. Dupuis-Girod S, Cottin V, Shovlin CL. The Lung in Hereditary Hemorrhagic Telangiectasia. Respiration. 2017;94(4):315-330. https://doi.org/10.1159/000479632

14. Shovlin $C L$, Guttmacher $A E$, Buscarini $E$, Faughnan $M E$, Hyland $\mathrm{RH}$, Westermann $\mathrm{CJ}$, et al. Diagnostic criteria for hereditary hemorrhagic telangiectasia (Rendu-Osler-Weber syndrome). Am J Med Genet. 2000;91(1):66-7. https://doi.org/10.1002/(SICI)10968628(20000306)91:1<66::AID-AJMG12>3.0.CO;2-P

15. dos Santos JW, Dalcin TC, Neves KR, Mann KC, Pretto GL, Bertolazi AN. Hereditary hemorrhagic telangiectasia: a rare cause of severe anemia. J Bras Pneumol. 2007;33(1):109-12. https://doi.org/10.1590/ S1806-37132007000100020

16. Juares AJ, Dell'Aringa AR, Nardi JC, Kobari K, Gradim Moron Rodrigues VL, Perches Filho RM. Rendu-Osler-Weber Syndrome: case report and literature review. Braz J Otorhinolaryngol. 2008;74(3):452-7. https://doi.org/10.1016/S1808-8694(15)30582-6

17. Santhirapala V, Williams LC, Tighe HC, Jackson JE, Shovlin $\mathrm{CL}$. Arterial oxygen content is precisely maintained by graded erythrocytotic responses in settings of high/normal serum iron levels, and predicts exercise capacity: an observational study of hypoxaemic patients with pulmonary arteriovenous malformations. PLoS One. 2014;9(3):e90777. https://doi.org/10.1371/journal.pone.0090777

18. Grocott MP, Martin DS, Levett DZ, McMorrow R, Windsor J, Montgomery HE, et al. Arterial blood gases and oxygen content in climbers on Mount Everest. N Engl J Med. 2009;360(2):140-9. https://doi.org/10.1056/NEJMoa0801581

19. Garcia-Tsao G, Korzenik JR, Young L, Henderson KJ, Jain D, Byrd $B$, et al. Liver disease in patients with hereditary hemorrhagic telangiectasia. N Engl J Med. 2000;343(13):931-6. https://doi. org/10.1056/NEJM200009283431305

20. Lyle MA, Fenstad ER, McGoon MD, Frantz RP, Krowka MJ, Kane GC, et al. Pulmonary Hypertension in Hereditary Hemorrhagic Telangiectasia. Chest. 2016;149(2):362-371. https://doi.org/10.1378/ chest. 15-0535

21. Hsu CC, Kwan GN, Thompson SA, Evans-Barns H, van Driel ML. Embolisation for pulmonary arteriovenous malformation Cochrane Database Syst Rev. 2015;1:CD008017. https://doi. org/10.1002/14651858.CD008017.pub4

22. Yasuda W, Jackson JE, Layton DM, Shovlin CL. Hypoxaemia, sport and polycythaemia: a case from Imperial College London. Thorax. 2015;70(6):601-3. https://doi.org/10.1136/thoraxjnl-2014-206381

23. Howard LSGE, Santhirapala V, Murphy K, Mukherjee B, Busbridge $\mathrm{M}$, Tighe $\mathrm{HC}$, et al. Cardiopulmonary exercise testing demonstrates maintenance of exercise capacity in patients with hypoxemia and pulmonary arteriovenous malformations. Chest. 2014;146(3):709718. https://doi.org/10.1378/chest.13-2988

24. Vorselaars VM, Velthuis S, Mager JJ, Snijder RJ, Bos WJ, Vos JA et al. Direct haemodynamic effects of pulmonary arteriovenous malformation embolisation. Neth Heart J. 2014;22(7-8):328-33. https://doi.org/10.1007/s12471-014-0539-7

25. Pierucci P, Murphy J, Henderson KJ, Chyun DA, White RI Jr. New definition and natural history of patients with diffuse pulmonary arteriovenous malformations: twenty-seven-year experience. Chest. 2008;133(3):653-61. https://doi.org/10.1378/chest.07-1949

26. Shovlin CL, Sodhi V, McCarthy A, Lasjaunias P, Jackson JE, Sheppard MN. Estimates of maternal risks of pregnancy for women with hereditary haemorrhagic telangiectasia (Osler-WeberRendu syndrome): suggested approach for obstetric services. BJOG. 2008;115(9):1108-15. https://doi.org/10.1111/j.1471 0528.2008.01786.x

27. Shovlin CL, Gibbs JS, Jackson JE. Management of pulmonary arteriovenous malformations in pulmonary hypertensive patients: a pressure to embolise? Eur Respir Rev. 2009;18(111):4-6. https://doi. org/10.1183/09059180.00011102

28. Lacombe P, Lacout A, Marcy PY, Binsse S, Sellier J, Bensalah $M$, et al. Diagnosis and treatment of pulmonary arteriovenous malformations in hereditary hemorrhagic telangiectasia: An overview. Diagn Interv Imaging. 2013;94(9):835-48. https://doi.org/10.1016/j. diii.2013.03.014

29. Woodward CS, Pyeritz RE, Chittams JL, Trerotola SO. Treated pulmonary arteriovenous malformations: patterns of persistence and associated retreatment success. Radiology. 2013;269(3):919-26. https://doi.org/10.1148/radiol.13122153

30. Chick JFB, Reddy SN, Pyeritz RE, Trerotola SO. A Survey of Pulmonary Arteriovenous Malformation Screening, Management, and Follow-Up in Hereditary Hemorrhagic Telangiectasia Centers of Excellence. Cardiovasc Intervent Radiol. 2017;40(7):1003-1009. https://doi.org/10.1007/s00270-017-1604-6

31. Vorselaars VM, Velthuis S, Snijder RJ, Westermann CJ, Vos JA, Mager JJ, et al. Follow-up of pulmonary right-to-left shunt in hereditary haemorrhagic telangiectasia. Eur Respir J. 2016;47(6):1750-7. https:// doi.org/10.1183/13993003.01588-2015 